\title{
Cross validation of analytical solutions against the computational model predictions of the response of semi floating energy pile
}

\author{
Arash Saeidi Rashk Olia ${ }^{1}$, and Dunja Perić ${ }^{1, *}$ \\ ${ }^{1}$ Kansas State University, Department of Civil Engineering, 1701C Platt St., Manhattan, KS 66506-5000, US
}

\begin{abstract}
In this study, responses of a single semi floating energy pile to a combined thermal and mechanical load are predicted by analytical and computational models. The axial compressive load applied at the pile head comprises the mechanical load while the thermal load is applied by prescribing the temperature difference history to the pile. The temperature difference is the difference between the temperatures of the pile and the surrounding soil. The energy pile is surrounded by a single uniform soil layer underlain by the bedrock, which is flush with the pile tip. A selected combination of thermal and mechanical loads resulted in an upward displacement, tensile strain and compressive stress in the case of heating. In the case of cooling the load combination resulted in a downward displacement, compressive strain and tensile stress. In spite of different methods of obtaining soil stiffness parameters for analytical and computational models the predictions of both methods are in a very good agreement.
\end{abstract}

\section{Introduction}

Energy piles are deep foundations with a dual role. They simultaneously transfer thermal energy and load between the superstructure and the subsurface. Transfer of thermal energy is achieved by embedding plastic pipes into an energy pile, thus providing a fluid conduit. Burger et al. [1] stated that temperature in the ground at depths of 3 to $5 \mathrm{~m}$ is constant and approximately equal to the mean annual air temperature. This enables storage of the excess heat in the ground during summers and its subsequent extraction during winters, thus providing the supplemental and sustainable space heating while lowering the carbon dioxide emission into the atmosphere. It is because the free thermal deformation of energy pile is restrained by the surrounding soil that displacement, stress and strain are induced in the pile during thermal loading. Consequently, design of energy piles requires the in depth understanding of the thermomechanical soil structure interaction. To this end, various researchers have performed numerical and physical modeling of energy piles. The former primarily uses finite Element Analysis (FEA) and finite difference method while the later typically includes full-scale in situ tests and geotechnical centrifuge tests.

This study presents a cross validation of FEA against the analytical solutions whereby axial displacement, strain and stress obtained by using the two methods are presented and compared.

\section{Analytical model}

Cossel 2019 [2] derived analytical solutions for thermomechanical soil structure interaction in a single energy pile subjected to a combined thermal and mechanical load. The former includes heating or cooling of the energy pile while the latter comprises an axial load applied at the pile head. Cossel [2] assumed that both, the pile and the soil pile interface remained in the elastic range while experiencing working stresses. This assumption was confirmed by several other researchers [3-7]. Consequently, a thermo-elastic constitutive law was adopted for the pile. Furthermore, the soil pile interface was modelled by a continuous elastic shear spring attached along the vertical pile boundary while a normal elastic spring was attached at the pile tip. The analytical solutions presented by Cossel [2] are used herein to obtain the predictions of the analytical model. Neither the computational nor the analytical models placed any restraints at the pile head.

\section{Material properties}

In order to cross validate the numerical model against analytical solutions a semi-hypothetical homogeneous soil profile was developed. For this purpose, one of the four soil layers surrounding the energy pile constructed and tested at Swiss Federal Institute of Technology Lausanne, Switzerland (Laloui et al. [4]) was chosen.

* Dunja Perić: peric@ksu.edu 
Based on laboratory classification tests, the results of which were provided by Laloui et al. [8], and in accordance with the Unified Soil Classification System each of the four soil layers at the site classifies as a low plasticity clay $(\mathrm{CL})$. These layers are underlain by the sandstone whose top surface is located at a depth of 25.5 meters. Specifically, the top two layers (A1 and A2) are alluvial glacial lacustrine deposits. In the present study, a single soil layer, representing the soil A1 from Laloui et al [4] is placed on top of the bedrock, which coincides with the pile tip elevation.

Elastic parameters of soil A1 used herein were determined by Perić et al. [5] based on the results of conventional triaxial tests reported by Laloui et al. [8]. The calibration resulted in the effective Young's moulds of $190 \mathrm{MPa}$ and in the effective Poisson's ratio of 0.22 . The remaining soil properties used in the computational model were taken from Laloui et al. [4]. Thus, the coefficients of thermal expansion, heat capacity and thermal conductivity for soil $\mathrm{A} 1$ are equal to $1 \times 10^{-5} /{ }^{\circ} \mathrm{C}$, $2.4 \times 10^{6} \mathrm{~J} /\left(\mathrm{m}^{3 \circ} \mathrm{C}\right)$ and $1.8 \mathrm{~W} /\left(\mathrm{m}^{\circ} \mathrm{C}\right)$ respectively. Furthermore, the values of the coefficients of thermal expansion, heat capacity and thermal conductivity for the bedrock are equal to $1 \times 10^{-6} /{ }^{\circ} \mathrm{C}, 2.0 \times 10^{6} \mathrm{~J} /\left(\mathrm{m}^{3 \circ} \mathrm{C}\right)$ and 1.1 $\mathrm{W} /\left(\mathrm{m}^{\circ} \mathrm{C}\right)$ respectively. Additionally, the effective elastic modulus of the $\mathrm{u}$ bedrock is equal to $1273.44 \mathrm{MPa}$ while its effective Poisson's ratio is equal to 0.157 . The hydraulic conductivities of soil A1 and the bedrock are equal to $2 \times 10^{-6} \mathrm{~m} / \mathrm{s}$ and $1 \times 10^{-15} \mathrm{~m} / \mathrm{s}$ respectively.

Knellwolf et al. [7] reported the stiffness values for the shear $\left(k_{s}\right)$ and normal $\left(k_{b}\right)$ springs replacing the surrounding soil, which were equal to $16.7 \mathrm{MPa} / \mathrm{m}$ and $1335.4 \mathrm{MPa} / \mathrm{m}$ respectively. These values were used herein to obtain the predictions of the analytical model.

The pile has the thermal expansion, heat capacity and thermal conductivity of $1 \times 10^{-5} /{ }^{\circ} \mathrm{C}, 2 \times 10^{6} \mathrm{~J} /\left(\mathrm{m}^{3 \circ} \mathrm{C}\right)$, and $2.1 \mathrm{~W} /\left(\mathrm{m}^{\circ} \mathrm{C}\right)$ respectively. Finally, the elastic modulus and the Poisson's ratio of the pile are equal to $29.2 \mathrm{GPa}$ and 0.177 respectively.

\section{Mechanical and thermal loads}

First, a compressive axial load having a magnitude of $1000 \mathrm{kN}$ was applied at the pile head. Next, the pile was subjected either to a net heating or net cooling. The former consists of a single heating/cooling cycle while the latter includes a single cooling/heating cycle. Corresponding temperature histories are shown in Table 1 whereby the positive temperature difference $(\Delta T)$ indicates heating of the energy pile with respect to the surrounding soil. It is noted that negative temperature difference does not necessarily indicate that the soil in freezing.

Table 1. Temperature histories for two loading scenarios

\begin{tabular}{|c|c|c|c|c|c|}
\hline Time (days) & 0 & 5 & 22 & 27 & 62 \\
\hline$\Delta \mathbf{T}\left({ }^{\circ} \mathbf{C}\right)$ & 0 & 9 & 14 & 6 & 2 \\
\hline$\Delta \mathbf{T}\left({ }^{\circ} \mathbf{C}\right)$ & 0 & -9 & -14 & -6 & -2 \\
\hline
\end{tabular}

\section{Computational model}

A coupled thermal hydro-mechanical FEA was performed by using the finite element software ABAQUS/CAE 2019. A deformed finite element mesh at $\Delta T=14^{\circ} \mathrm{C}$ is depicted in Figure 1 along with the superimposed color plot of nodal temperatures. The pile diameter and length are equal to $1 \mathrm{~m}$ and $26 \mathrm{~m}$ respectively in accordance with Laloui et al. [3]. Horizontal displacement is prevented along the vertical boundaries, while the full fixity was enforced along the bottom boundary.

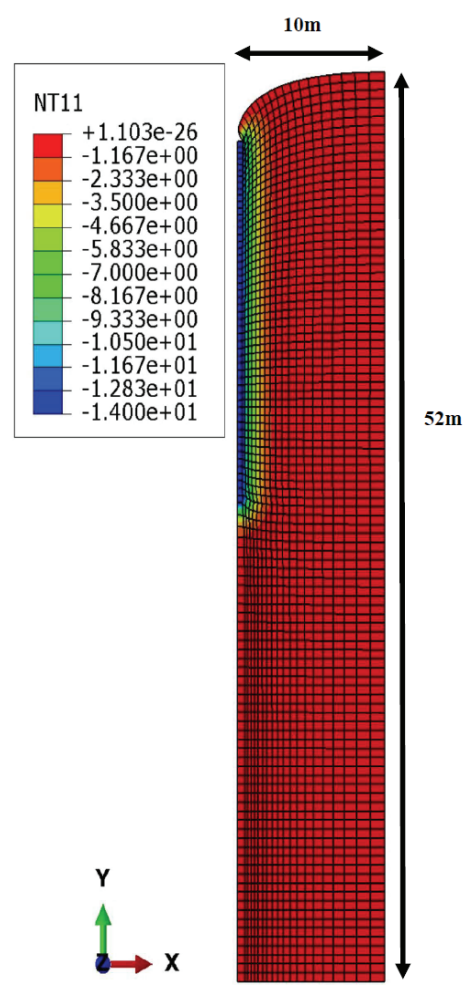

Fig. 1. Temperature distribution (in ${ }^{\circ} \mathrm{C}$ ) corresponding to $\Delta \mathrm{T}=-14^{\circ} \mathrm{C}$ predicted by the computational model (deformation scale factor $=2200$ )

The FEA was conducted in two steps. The first step comprised solely thermal analysis while the second step included a coupled pore pressure displacement analysis. The temperature distribution obtained from the first step served as the input into the second step, at the beginning of which, an axial load having magnitude of $1000 \mathrm{kN}$ was applied at the pile head. The load was ramped linearly versus time over the period of 8 months. A rough contact between the pile and soil was used in accordance with the assumption of elastic states of the soil and the pile. Moreover, it was assumed that temperature is uniformly distributed in the interior of the pile in both, analytical and computational models.

The heat transfer analysis was conducted by using the eight-node quadratic axisymmetric heat transfer quadrilateral elements (DCAX8). The fully coupled pore pressure displacement analysis was performed by using the eight-node biquadratic axisymmetric quadrilateral 
elements with reduced integration (CAX8RP) for the soil and the bedrock, and the eight-node biquadratic axisymmetric quadrilateral elements with reduced integration (CAX8R) for the pile.

\section{Cross validation}

Predictions of axial displacement, strain and stress in the energy pile obtained from analytical and numerical models are presented next. Tensile strain and stress are positive and upward displacement is also positive. Vertical displacement of the pile head versus time is depicted in Figure 2. As expected, the axial compressive load had induced a downward displacement prior to the heating. The expansion and contraction of the pile due to heating or cooling scenarios respectively reach their extreme values at the largest temperature difference $\left( \pm 14^{\circ} \mathrm{C}\right)$ in both, analytical and numerical predictions. Pile expansion in the net heating scenario compensates the downward displacement due to the compressive load. On the contrary cooling increases the initial downward displacement caused by the compressive load. Specifically, the mechanically induced initial downward displacement at the pile head is fully compensated by the upward thermally induced displacement at the temperature difference of about $3^{\circ} \mathrm{C}$ to $4^{\circ} \mathrm{C}$ in the case of net heating.

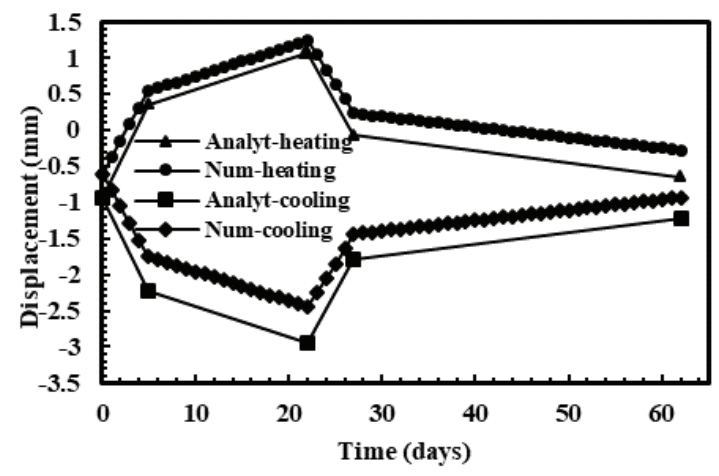

Fig. 2. Vertical pile head displacement versus time for net heating and net cooling.

Axial displacement of the pile along its depth at five and 22 days after the beginning of the thermal loading is shown in Figures 3 and 4. As expected in the case of a semi floating pile the existence of a null point is evident in all predictions. In the case of net heating the pile region located above the null point moves upward while the region below the null point moves downward and vice versa in the case of net cooling. It is noted that the location of zero axial displacement in Figures 3 and 4 corresponds to a combined null point rather than the thermal null point. Specifically, in the case of a semi floating pile a null point does not exist for a sole mechanical load. On the contrary, a null point exists in the case of a sole thermal load. Nevertheless, because the magnitudes of thermal and mechanical loads selected herein are such that the thermal load is dominant for the most part, as explained above, the combined null point is present. In addition to the load combination, the location of the null point is also affected by the soil-pile interface stiffness and the bedrock stiffness.

Figure 3 shows that the maximum displacement occurs at the pile head while the minimum displacement occurs at the pile tip in the case of net heating. This trend is completely opposite for the net cooling scenario. While the axial displacement predictions of numerical and analytical models are in good agreement for net heating and net cooling the predictions of a combined null point are in better agreement in the case of net cooling.

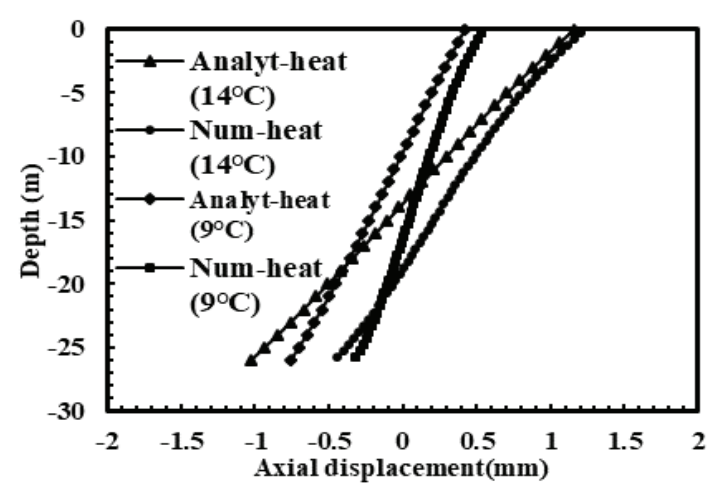

Fig. 3 Axial displacement in the pile versus depth at $\Delta T=9^{\circ} \mathrm{C}$ and $14^{\circ} \mathrm{C}$

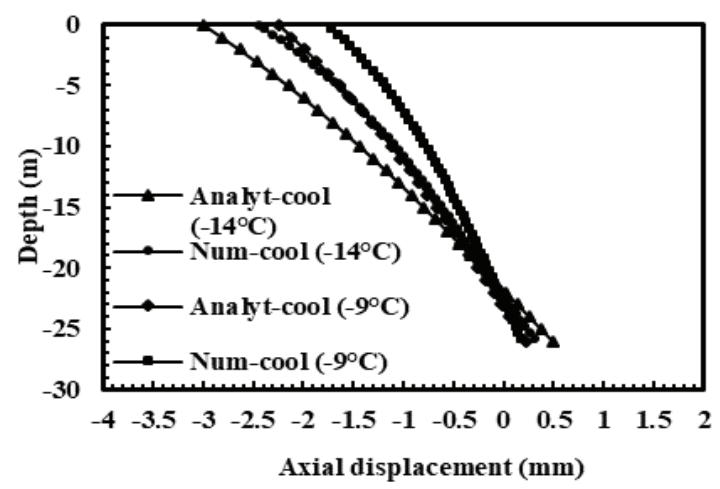

Fig. 4. Axial displacement in the pile versus depth at $\Delta T=-$ $9^{\circ} \mathrm{C}$ and $-14^{\circ} \mathrm{C}$

Axial strain in the pile versus depth predicted by the two models also shows a reasonable agreement as depicted in Figures 5 and 6. Since the axial displacement of the pile head due to the mechanical load was compensated by the heating to $\Delta T=3^{\circ} \mathrm{C}$ to $4^{\circ} \mathrm{C}$, it can be inferred that the effects of thermal load are dominant for the larger temperature differences. Therefore, the combination of a tensile strain induced by heating and compressive strain induced by the mechanical load results in the tensile axial strain in the case of a combined thermal and mechanical load. It can also be observed that the discrepancy between the predictions of the two models slightly increases with increase in the temperature difference. This is due to the fact that soil stiffness used in the computational and analytical models are not necessarily equivalent. As mentioned previously 
the former was obtained in the laboratory from the conventional triaxial tests while the later was obtained from the full scale in situ pile test. Consequently, the larger the displacement of the pile, the larger is the difference between the predictions of the two models. This also explains why the discrepancy is larger in the case of cooling than in the case of heating. Precisely, a combination of the cooling and the compressive axial load results in the larger magnitude of displacement than the combination of the heating and the compressive axial load. It is also noted that the displacement of a semi floating pile is affected by the stiffness of the soil surrounding the pile along its shaft and its tip. Contrariwise, in the case of an end bearing pile the tip displacement obtained from both, numerical and analytical predictions is nearly equal to zero. Thus, the discrepancy between the two methods in this case is primarily the consequence of different stiffness along the pile shaft only.

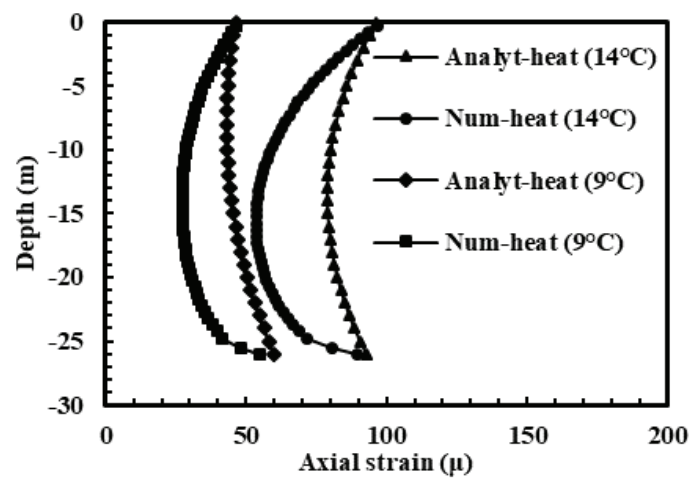

Fig. 5. Axial strain in the pile versus depth at $\Delta T=9^{\circ} \mathrm{C}$ and $14^{\circ} \mathrm{C}$

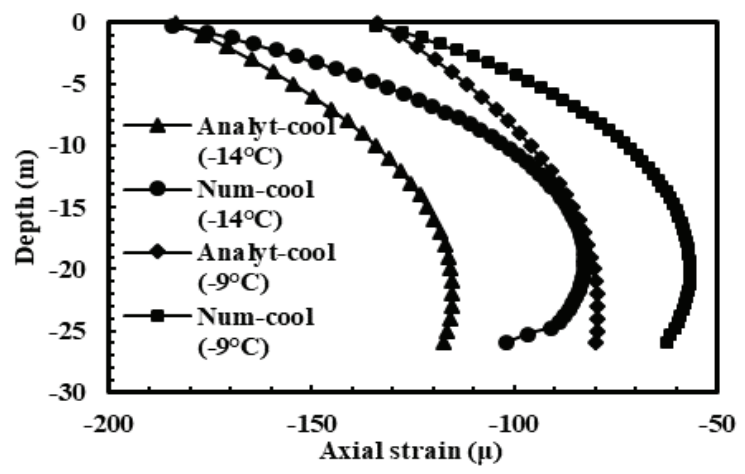

Fig. 6. Axial strain in the pile versus depth at $\Delta T=-9^{\circ} \mathrm{C}$ and $14^{\circ} \mathrm{C}$

The numerical and analytical predictions of the axial stress in the pile versus depth at five and 22 days after the beginning of the net heating and the net cooling are shown in Figures 7 and 8 respectively. While the net heating scenario induces a compressive stress in the energy pile, the net cooling generates tensile stress in the pile. Nevertheless, in the case of a combined cooling and mechanical load the length of the tensile zone is highly dependent on the magnitude of the axial compressive force and the amount of a decrease in the temperature difference. Likewise, the discrepancy in the predicted stresses increases with decreasing temperature difference. The predictions of mechanically induced stress show very good agreement as shown in Figures 7 and 8 . It can be observed from Figure 7 that the combination of compressive force and heating increases the compressive stress above the mechanically induced stress. In case of cooling, the combined stress remains compressive in the top portion of the pile and changes to tensile stress in the bottom portion. The length of the tensile zone increases with decreasing temperature difference.

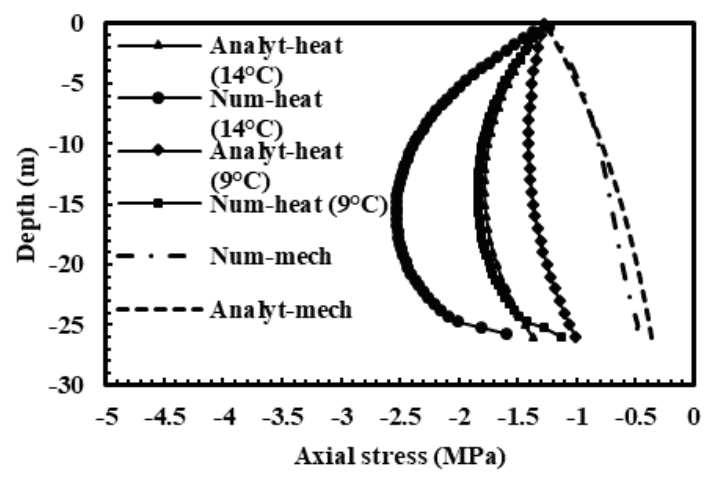

Fig. 7. Axial stress in the pile versus depth at $\Delta T=9^{\circ} \mathrm{C}$ and $14^{\circ} \mathrm{C}$

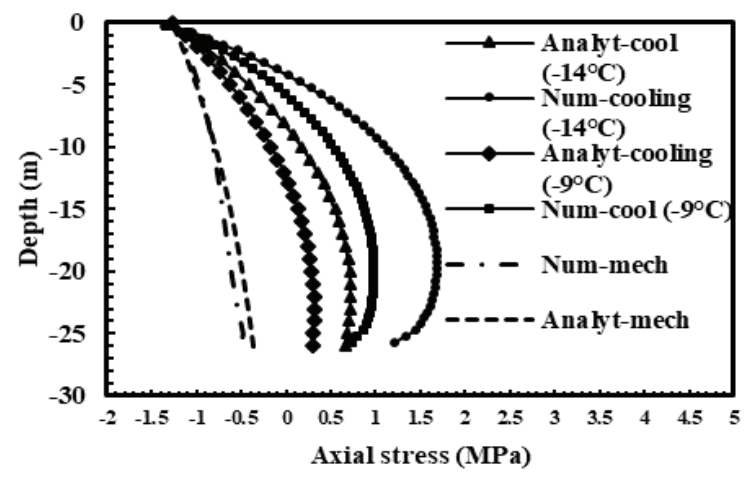

Fig. 8. Axial stress in the pile versus depth at $\Delta T=-9^{\circ} \mathrm{C}$ and $14^{\circ} \mathrm{C}$

\section{Conclusions}

Predictions of a coupled thermo-hydro-mechanical FEA of a semi floating energy pile were cross validated against the predictions obtained from the analytical model. Both models predicted equal trends of change of axial displacement, strain and stress versus depth resulting in a reasonable discrepancy for heating/cooling to $\pm 14^{\circ} \mathrm{C}$.

Furthermore, both models predicted tensile strain for the net heating scenario, and compressive strain for the net cooling. It was observed that heating induces a compressive stress in the energy pile, while cooling induces a tensile stress. The length of the tensile zone 
developed in the case cooling depends on the magnitude of the mechanical and thermal loads. Nevertheless, the presence of a tensile zone should be taken into consideration during the pile design due to the concrete vulnerability in tension. In addition, the pile tip needs to be securely anchored into the bedrock in cases, in which development of a tensile stress is likely.

The discrepancy between the predictions of the two models was found to be proportionate with the temperature difference. Nevertheless, the discrepancy is primarily due to different displacements occurring at different temperature differences. This also explains a larger discrepancy in the net cooling scenario, which develops because thermally and mechanically induced displacements are both directed downward in the top portion of the pile.

It is believed that the actual source of discrepancy lies in non-equivalent soil stiffness parameters used in computational and analytical models. Specifically, the soil stiffness used in the analytical model was determined from the full scale in situ test while the soil stiffness used in the computational model was determined from the conventional triaxal tests that were conducted in the laboratory.

\section{References}

1. A. Burger, E. Recordon, D. Bovet, L. Cotton, \& B. Saugy, "Thermique des Nappes Souterraines" Presses Polytechniques Romandes. Laussane, Switzerland (1985).

2. A. Cossel. "Analytical solutions for thermomechanical soil structure interaction in energy piles." Kansas State University, MS thesis (2019).

3. D. Perić, A. Cossel, \& E. Sarna, S. A. "Analytical Solutions for Thermomechanical Soil Structure Interaction in End-Bearing Energy Piles". Journal of Geotechnical and Geoenvironmental Engineering, 146(7), 04020047 , https://doi.org/10.1061/(ASCE)GT.19435606.0002269 .

4. L. Laloui, M. Nuth, \& L. Vulliet. "Experimental and numerical investigations of the behaviour of a heat exchanger pile" International Journal for Numerical and Analytical Methods in Geomechanics, 30(8), 763-781, (2006). https://doi.org/10.1002/nag.499.

5. D. Perić, T. V. Tran, \& M. Miletić, "Effects of soil anisotropy on a soil structure interaction in a heat exchanger pile" Computers and Geotechnics, 86, 193-202,

(2017). https://doi.org/10.1016/j.compgeo.2017.01.005.

6. C. Iodice, R. Di Laora, \& A. Mandolini, "Analytical Solutions for Ultimate Limit State Design of Thermal Piles, "Journal of Geotechnical and Geoenvironmental Engineering, 146(5), 04020016 ,

(2020). https://doi.org/10.1061/(ASCE)GT.19435606.0002204.

7. C. Knellwolf, H. Peron, \& L. Laloui, "Geotechnical analysis of heat exchanger piles," Journal of Geotechnical and Geoenvironmental Engineering,
137(10), 890-902, https://doi.org/10.1061/(ASCE)GT.1943-

(2011). 5606.0000513.

8. L. Laloui, M. Moreni, G. Steinmann, L. Vulliet, A. Fromentin, D. Pahud, "Heat exchanger pile: effect of the thermal solicitations on its mechanical properties" Report of the Swiss Federal Office of Energy, (1999). 